\title{
To define factors of stressor in families with depressive member Zahra Ghazavi*
}

\author{
Address: Isfahan University of Medical Science, Psychiatric Nursing Department, Iran
}

* Corresponding author

\author{
from International Society on Brain and Behaviour: 2nd International Congress on Brain and Behaviour \\ Thessaloniki, Greece. 17-20 November 2005 \\ Published: 28 February 2006 \\ Annals of General Psychiatry 2006, 5(Suppl I):S304 doi:I0.I 186/I744-859X-5-SI-S304
}

\section{Background}

Stress is the most common issue in people's daily life and it is plague in modern century. That influenced lives of millions of people. The problem that attached people's mental and physical health at the same time, at this century advanced thecnology proceed very fast and causes people to be depressed and deprivated, and people have conflicts and contrast that causes depression in family members.

\section{Materials and methods}

This study is a single stage descriptive analytic case-control are performed in mental clinics in Isfahan. As control 170 healthy families and as case 70 families having a depressed member in referring to the mental clinics were selected by convenient method. The data were gathered by questionnaires in cluding some family demographic characterictics in the first part a check list of stressful events in family in the second part were investigated in both case and control groups.

\section{Results}

The findings showed $47.5 \%$ of the subjects in control group had the least number of stressful events (1 to 2) while in study group 33\% the of the subjects had the highest stressful events ( 3 to 4 ). On the whole, mean defference test (3. 74 for study and 2.2 for control) showed a significant difference.

\section{Discussion}

Regarding the findings suggesting that the association between environmental stressful factors such as death and other lacks, and depression. The findings also showed among 20 factors of stress, families with a depressed member experience higher stress than the others. 